\title{
Komplikasi Neurologis dan Non-Neurologis Prosedur Digital Subtraction Angiography Serebral di RSUD Dr.Moewardi Periode Juni 2013-Mei 2018
}

\author{
Subandi $^{1}$, Pepi Budianto ${ }^{1}$, Stefanus Erdana Putra ${ }^{2}$, Wahyu Gusti Randa ${ }^{1}$ \\ 1. Program Studi Pendidikan Dokter Spesialis Ilmu Penyakit Saraf, Fakultas Kedokteran \\ Universitas Sebelas Maret \\ 2. RSUD Gunungsitoli, Kabupaten Nias
}

Korespondensi : stefanuserdanaputra@gmail.com

\begin{abstract}
ABSTRAK
Pendahuluan: Digital subtraction angiography (DSA) serebral menjadi gold standard untuk memeriksa penderita dengan gangguan serebrovaskular. Banyak kemajuan yang telah diperoleh untuk meningkatkan keamanan penggunaan DSA serebral, seperti kontras yang lebih aman, kateter yang lebih kecil, kawat (hydrophilic guides), dan sistem pengamatan digital yang semakin baik. Hingga saat ini, belum ada penelitian terkait komplikasi neurologis maupun non-neurologis dari prosedur DSA yang dilakukan di Indonesia. Tujuan penelitian ini adalah mengetahui berbagai komplikasi prosedur DSA, sehingga operator dapat meminimalisasi timbulnya komplikasi tersebut saat prosedur DSA dilakukan di kemudian hari.

Metode penelitian: Penelitian deskriptif dilakukan di RSUD Dr. Moewardi terhadap 486 pasien yang menjalani prosedur DSA. Data yang dikumpulkan meliputi umur, jenis kelamin, komplikasi, serta temuan angiografi. Komplikasi neurologis dan non neurologis dikelompokkan menjadi: early, yang akan menghilang kurang dari 7 hari dan late, bila komplikasi terjadi lebih dari 7 hari. Kriteria inklusi pada penelitian ini adalah semua pasien yang menjalani prosedur DSA di RSUD. Dr. Moewardi periode Juni 2013 hingga Mei 2018 dan pasien yang mengalami komplikasi neurologis dan non-neurologis.

Hasil penelitian: Terdapat 15 (3\%) dari 486 pasien yang menjalani prosedur DSA serebral mengalami komplikasi. Komplikasi neurologis early terjadi pada 10 kasus (2\%), dan tidak didapatkan komplikasi pada tipe late, sedangkan komplikasi non-neurologis early terjadi pada 2 kasus $(0.4 \%)$, dan late pada 3 kasus $(0.6 \%)$. Kejadian ini sebanding dengan penelitian yang dilakukan oleh studi internasional lainnya.

Kesimpulan: Prosedur DSA serebral relatif aman, baik dalam hal komplikasi neurologis, komplikasi non-neurologis maupun terjadinya kematian. Komplikasi neurologis yang terjadi masih dalam batas yang direkomendasikan sesuai dengan petunjuk keamanan untuk melakukan DSA serebral.
\end{abstract}

Kata kunci: Angiografi serebral, keamanan, komplikasi

\begin{abstract}
Introduction: Cerebral digital subtraction angiography (DSA) is a gold standard to examine patients with cerebrovascular disorders. Much progress has been made to improve the safety of cerebral DSA, such as safer contrast, smaller catheters, hydrophilic guides, and improved digital surveillance systems. Until now, there have never been any studies related to neurological or non-neurological complications of DSA procedures conducted in Indonesia. The purpose of this study is to determine the various complications, so that the operator can prevent them when performing DSA procedure later.

Methods: Descriptive study was conducted in Dr. Moewardi hospital. Total of 486 patients underwent DSA procedures. The data include age, sex, complications, and angiographic findings. Neurological and non-neurological complications were grouped into: early, which disappeared less than 7 days, late, if the complications occur more than 7 days. The inclusion criteria all patients undergoing DSA procedures in Dr. Moewardi hospital
\end{abstract}


between June 2013 and May 2018 as well as patients with neurological and nonneurological complications.

Results: Of the total study subjects ( $n=486$ patients), 15 patients (3\%) experienced complication. Early neurological complications occurred in 10 cases (2\%), and there were no late type complications, whereas early non neurological complications occurred in 2 cases $(0.4 \%)$, and delayed in 3 cases $(0.6 \%)$. This incidence is equal which conducted to another international study.

Conclusions: A cerebral DSA procedures is relatively safe. The neurological complications which occur are still within the recommended limits in accordance with the safety instructions for performing cerebral DSA.

Keywords: Cerebral angiography, safety, complications

\section{PENDAHULUAN}

Sejarah dan perkembangan keahlian neurointervensi secara umum dan pemeriksaan cerebral DSA (C-DSA) pada khususnya $^{1}$, tidak terlepas dari upaya dan kerja keras dari beberapa orang neurolog di Eropa, seperti Egaz Moniz dan Peirre Lasjaunias yang merupakan pionir dari neurointervensi ${ }^{2}$. C-DSA sendiri merupakan modifikasi dari angiografi serebral, suatu upaya diagnostik dengan cara menginjeksikan kontras ke arah pembuluh darah otak yang akan diperiksa atau pembuluh darah yang menuju ke otak melalui kateter.

C-DSA sebenarnya sangat membantu para neurolog karena banyak penyakit dalam bidang neurologi yang disebabkan oleh kelainan pada pembuluh darah baik di daerah ekstra maupun intrakranial, misalnya transient ischemic attack (TIA), stroke iskemik yang berulang, perdarahan sub-arakhnoid spontan, aneurisma, malformasi arteri-vena, vasospasme intrakranial, tumor-tumor yang berada di daerah kepala, fistula yang berbentuk baik dural arteriovenous maupun carotid cavernous, dan keadaan-keadaan lainnya untuk melihat bentuk anatomi ataupun kolateral yang ada baik pada pembuluh darah ekstra maupun intrakranial ${ }^{2,3}$.

Sementara itu, angka komplikasi CDSA yang timbul amatlah bervariasi. Dari rangkuman beberapa penelitian yang ada di luar negeri, angka komplikasi keseluruhan berkisar antara 0,05\%-4,5\% di mana $85 \%$ $90 \%$ dari angka tersebut bersifat reversibel. ${ }^{3}$ Komplikasi yang paling parah selain kematian adalah stroke (iskemik/perdarahan), TIA, gangguan orientasi, hematoma, luka pada bidang tindakan yang tidak kunjung sembuh, dan nyeri pada lokasi bekas tindakan. Pada pasien anak, tindakan DSA aman untuk dilakukan $^{2,3}$.

Sampai saat ini, belum pernah ada penelitian yang secara detail melaporkan kejadian komplikasi C-DSA yang dilakukan pada pasien usia dewasa di Indonesia. ${ }^{4}$ Padahal tindakan C-DSA ini telah cukup banyak diterapkan di Indonesia dalam penegakan diagnosis. ${ }^{5}$ Oleh karena itu, mendukung keterbaharuan penelitian ini yang bertujuan untuk mengetahui berbagai komplikasi prosedur DSA, khusunya di RSUD Dr. Moewardi Periode Juni 2013-Mei 2018.

\section{METODE}

Penelitian ini dilaksanakan di Rumah Sakit Umum Daerah Dr. Moewardi Surakarta pada periode Juni 2013 sampai dengan Mei 2018 dengan desain deskriptif. Subyek penelitian ditentukan secara purposive sampling yaitu dengan mendata pasien yang menjalani DSA serebral yang sesuai dengan kriteria inklusi dan ekslusi sehingga memenuhi jumlah yang memenuhi syarat analisis. Data yang dikumpulkan meliputi umur, jenis kelamin, komplikasi, serta temuan 
angiografi melalui pengumpulan data rekam medis

Kriteria inklusi pada penelitian ini adalah semua pasien yang menjalani prosedur DSA di RSUD. Dr. Moewardi periode Juni 2013 hingga Mei 2018 dan pasien yang mengalami komplikasi neurologis dan nonneurologis. Peneliti mengekslusikan pasien yang tidak mengalami komplikasi selama prosedur DSA. Penelitian ini telah dinyatakan layak etik oleh Komisi Etik Penelitian Kesehatan RSUD Dr. Moewardi melalui Surat Kelaikan Etik nomor 742/VI/HREC/2020.

\section{HASIL}

Tabel 1. Demografi Pasien

\begin{tabular}{|c|c|}
\hline & Jumlah \\
\hline \multicolumn{2}{|l|}{ Umur } \\
\hline$<17$ tahun & 12 \\
\hline$>17$ tahun & 474 \\
\hline \multicolumn{2}{|l|}{ Jenis kelamin } \\
\hline Laki-laki & 285 \\
\hline Perempuan & 201 \\
\hline
\end{tabular}

Tabel 2. Daftar Komplikasi

\begin{tabular}{|c|c|c|}
\hline Jenis Komplikasi & Jumlah & $\begin{array}{c}\text { Waktu } \\
\text { Pemulihan }\end{array}$ \\
\hline \multicolumn{3}{|l|}{ Neurologis - } \\
\hline Early & 1 & 3 menit \\
\hline Kejang & 1 & 60 menit \\
\hline TIA/Stroke & 2 & 60 menit dan \\
\hline Blindness & & 24 jam \\
\hline & 1 & 48 jam \\
\hline $\begin{array}{l}\text { Vertigo } \\
\text { Nyeri kepala }\end{array}$ & 5 & $\begin{array}{l}2 \text { hari, } 3 \text { hari, } \\
3 \text { hari, } 5 \text { hari, } \\
5 \text { hari }\end{array}$ \\
\hline & $\begin{array}{l}\text { Tidak } \\
\text { ada }\end{array}$ & - \\
\hline \multicolumn{3}{|l|}{ Neurologis - Late } \\
\hline $\begin{array}{l}\text { Non-neurologis - } \\
\text { Early } \\
\quad \text { Hematoma }\end{array}$ & 2 & $\begin{array}{l}24 \text { jam dan } 48 \\
\text { jam }\end{array}$ \\
\hline $\begin{array}{l}\text { puncture } \\
\text { Non-neurologis - } \\
\text { Late }\end{array}$ & 3 & $\begin{array}{l}8 \text { hari, } 8 \text { hari, } \\
10 \text { hari }\end{array}$ \\
\hline $\begin{array}{l}\text { Hematoma } \\
\text { puncture }\end{array}$ & & \\
\hline
\end{tabular}

Tabel 3. C-DSA Periode Juni 2013-Mei 2018 di RSUD Dr. Moewardi

\begin{tabular}{lll}
\hline \multicolumn{1}{c}{ Temuan Kasus } & Jumlah & Tindakan \\
\hline Normal & 133 & \\
Stenosis Ekstrakranial & 9 & \\
Stenosis Intrakranial & 229 & \\
$\quad$ ICA & 41 & \\
$\quad$ MCA & 67 & Stenting \\
ACA & 51 & carotis (4) \\
$\quad$ Vertebral & 32 & \\
$\quad$ Basiler & 14 & \\
$\quad$ PCA & 24 & Embolisas \\
Arteriovenous & & i (23) \\
Malformation Cerebral & 34 & \\
Arteriovenous & & \\
Malformation Spinal & 2 & Coiling \\
& & $(19)$ \\
Aneurisma & & Embolisasi \\
& 27 & $(7)$ \\
Fistula Dural & 9 & \\
Cerebral Venous & 29 & Embolisasi \\
Thrombosis & & \\
Carotid Cavernous & 14 & \\
Fistula (CCF) & & \\
\hline
\end{tabular}

\section{PEMBAHASAN}

Terdapat 486 prosedur DSA serebral yang telah dilakukan pada bulan Juni 2013 hingga Mei 2018 (Tabel 1). Mayoritas subjek adalah laki-laki (59\%), berusia di atas 17 tahun (98\%), yang dilakukan DSA atas indikasi stenosis intrakranial $(47 \%)$. Dari seluruh prosedur tersebut, terjadi 10 kasus komplikasi neurologis dan 5 kasus komplikasi non-neurologis sebagaimana tercantum dalam Tabel 2. Setelah dilakukan DSA (Tabel 3), terlihat bahwa temuan kasus bervariasi terdiri dari 9 subjek stenosis ekstrakranial, 229 subjek stenosis intrakranial, 34 subjek arteriovenous malformation cerebral, 2 subjek arteriovenous malformation spinal, 27 subjek aneurisma, 9 subjek fistula dural, 29 subjek cerebral venous thrombosis, 14 subjek carotid cavernous fistula, serta 133 subjek normal.

Banyak faktor yang berperan dalam terjadinya komplikasi angiografi serebral seperti umur pasien, banyaknya kontras yang 
digunakan, panjangnya durasi tindakan, penggunaan lebih dari satu macam kateter, dan adanya hipertensi sistolik. Pasien dengan TIA atau stroke cenderung memiliki risiko komplikasi yang lebih tinggi dibandingkan dengan pasien subarachnoid hemorrhage (SAH), aneurisma serebral atau arteriovenous malformation (AVM). Usia rata-rata pasien TIA atau stroke sekitar sepuluh tahun lebih tua dari usia rata-rata pasien dengan $\mathrm{SAH}$, aneurisma serebral atau $\mathrm{AVM}^{6}$. Banyaknya kelainan neurologis yang dikaitkan dengan angiografi serebral sebenarnya disebabkan oleh penyakit serebrovaskuler yang mendasarinya daripada prosedur angiografi itu sendiri ${ }^{7}$.

Dalam penelitian ini, ditemukan satu kejadian kejang selama tiga menit $(0,2 \%)$ setelah prosedur angiografi serebral. Terjadinya komplikasi neurologis berupa kejang pada SAH, aneurisma serebral, dan AVM dapat disebabkan karena re-bleeding aneurisma yang bukan disebabkan oleh prosedur angiografi tetapi akibat riwayat medis pasien yang tidak tertangani atau ruptur aneurisma serebral. Hal ini sesuai dengan data penelitian sebelumnya yang menyebutkan risiko komplikasi neurologis berupa kejang bernilai kurang dari $0,07 \%{ }^{3}$.

Sementara itu, ditemukan juga satu kejadian TIA selama 60 menit $(0,2 \%)$ setelah prosedur angiografi serebral dalam penelitian ini. Penelitian sebelumnya oleh Barlin dan Alexandrov menyebutkan bahwa dalam jangka waktu 24-72 jam setelah prosedur angiografi serebral, terdapat sekitar $1 \%$ kejadian TIA dan $0,2 \%$ defisit neurologis persisten. Kejadian ini lebih mungkin berasal dari riwayat penyakit pasien (terutama emboli sekunder karena aterosklerosis) daripada prosedur angiografi itu sendiri ${ }^{8}$. Risiko rebleeding selama prosedur angiografi cukup rendah pada kasus SAH sekunder dengan ruptur aneurisma. Tidak ada kasus perdarahan ulang yang terjadi selama angiografi pada 415 kasus SAH akut dalam penelitian meta analisis yang juga dilakukan oleh Dion et $a l^{9}$. Risiko perdahan ulang dalam 24 jam pertama setelah SAH adalah 4\% dan 1-2\% untuk setiap hari berikutnya selama empat minggu setelah onset.

Stroke atau TIA setelah angiografi serebral merupakan komplikasi yang dapat terjadi. Faktor risiko terjadinya stroke setelah angiografi serebral adalah usia lanjut, adanya faktor komorbid vaskuler, dan risiko terkait tindakan. Jenis stroke yang paling umum terjadi adalah stroke emboli yang disebabkan oleh lepasnya plak aterom. Risiko terjadinya stroke setelah angiografi dilaporkan sebesar 0,07\%-7\% dalam 36 jam pertama setelah prosedur dilakukan. Risiko terjadinya stroke juga dipengaruhi oleh lamanya waktu saat fluoroskopi yang memungkinkan terjadinya banyak manipulasi pada kateter dan menyebabkan lepasnya plak aterom. Selain itu, banyaknya kontras yang digunakan juga mempengaruhi risiko terjadinya stroke ${ }^{10}$.

Kejadian blindness setelah prosedur angiografi serebral dalam penelitian ini ditemukan pada dua subjek $(0,4 \%)$ dengan lama waktu pemulihan masing-masing 60 menit dan 24 jam. Kejadian blindness merupakan kejadian yang jarang setelah prosedur angiografi serebral. Biasanya kejadian ini berlangsung dalam hitungan jam sampai lima hari. Hal yang mendasari blindness belum sepenuhnya diketahui. Beberapa teori menyebutkan adanya gangguan permeabilitas sawar darah otak di lobus oksipital yang disebabkan oleh neurotoksisitas akibat penggunaan kontras. Teori lain menyebutkan kejadian ini mungkin juga dipicu oleh posisi supine yang berkepanjangan selama prosedur angiografi serebral. Sirkulasi posterior diketahui lebih rentan terhadap cedera dan mungkin berhubungan dengan perbedaan inervasi sistem saraf simpatis. Risiko ini meningkat pada pasien dengan gangguan fungsi ginjal yang menyebabkan gangguan pada clereance ginjal terhadap zat kontras ${ }^{11}$. 
Dalam penelitian ini, ditemukan juga komplikasi neurologis lain berupa satu kasus vertigo $(0,2 \%)$ dan lima kasus nyeri kepala $(1 \%)$. Nyeri kepala setelah angiografi serebral dilaporkan muncul sebanyak $35 \%$ pada salah satu studi yang terjadi dua jam setelah prosedur angiografi serebral ${ }^{12}$. Peneliti tidak dapat mengindentifikasi nyeri kepala yang khas setelah angiografi serebral dalam penelitian ini, karena kemungkinan penyebabnya berasal dari berbagai etiologi. Jenis kelamin perempuan merupakan salah satu faktor risiko nyeri kepala setelah angiografi serebral yang kemungkinan disebabkan oleh faktor hormonal atau penurunan ambang batas nyeri ${ }^{13}$. Pada empat kasus onset vasospasme intra angiografi yang terjadi di regio posterior otak, dilaporkan adanya perkembangan aura tipikal yang secara bertahap menjadi nyeri kepala ${ }^{12}$. Satu kasus dilaporkan mengalami vasodilatasi pembuluh darah meninges di fronto-temporal 24 jam setelah onset nyeri kepala migraine, kemungkinan disebabkan rangsangan langsung atau tidak langsung pada arteri yang menginduksi fenomena cortical spreading depression $^{13}$. Penelitian sebelumnya menyatakan bahwa timbulnya nyeri kepala berulang setelah prosedur angiografi serebral disebabkan adanya hubungan dengan nyeri kepala sebelumnya. Pada penelitian tersebut juga dijelaskan bahwa $19 \%$ pasien mengeluhkan nyeri kepala pertama kali setelah prosedur angiografi serebral sedangkan $22,5 \%$ pasien mengeluhkan nyeri kepala berulang enam bulan setelah prosedur angiografi ${ }^{12,13}$.

Sementara itu, vertigo pasca angiografi serebral disebabkan oleh injury reperfusi yang menginduksi aritmia. Aritmia yang dapat terjadi adalah ventricular premature contractions, ventricular tachycardia, idioventricular rhythm, atrial fibrilasi, ventrikel fibrilasi, dan atrioventricular (AV) blok. Beberapa kondisi aritmia merupakan penanda berhasilnya reperfusi dan pada beberapa kasus aritmia dapat menjadi suatu penanda kerusakan sel dan iskemik yang dapat menimbulkan suatu gejala vertigo ${ }^{14}$.

Pada penelitian ini, ditemukan lima kasus komplikasi non-neurologis berupa hematoma groin pada regio inguinal kanan yang menjadi lokasi tempat penusukan (puncture) pasca prosedur angiografi serebral. Risiko komplikasi non-neurologis tidak dapat dievaluasi untuk pasien dengan SAH atau indikasi lain pada angiografi serebral karena kurangnya data yang didapat pada studi meta analisis sebelumnya. Risiko keseluruhan dari komplikasi non-neurologis sangat rendah $(0,6 \%)$. Hanya satu komplikasi nonneurologis yang ireversibel yang terjadi pada 3.517 pasien dalam studi meta analisis yang dilakukan oleh Dion et al. Komplikasi nonneurologis disebabkan faktor usia pasien (lebih dari 50 tahun), hipertensi, TIA sebagai indikasi, dan adanya bruit arteri carotis9. Sementara itu, penelitian sebelumnya oleh Usman menyatakan bahwa tidak ditemukan adanya komplikasi neurologis, nonneurologis, maupun kematian pada semua pasien anak yang menjalani prosedur DSA serebral karena kasus stroke dan non-stroke pada beberapa rumah sakit di Indonesia ${ }^{5}$.

Risiko DSA pada pasien dengan TIA atau stroke iskemik cenderung lebih tinggi dibandingkan pasien dengan indikasi lain saat prosedur angiografi serebral. Akan tetapi, hal ini masih sulit dibandingkan secara statistik. Risiko angiografi serebral pada pasien dengan penyakit selain TIA atau stroke, seperti SAH, aneurisma serebral, dan AVM lebih rendah dikarenakan Computed Tomography (CT) angiografi tidak lebih baik untuk digunakan dalam pelacakan aneurisma serebral dibandingkan angiografi serebral; angiogram kedua tidak dibenarkan pada pasien dengan SAH ketika tidak ditemukan adanya sumber perdarahan pada angiogram pertama; dan Magnetic Resonance (MR) angiografi atau angiografi serebral tidak harus digunakan 
sebagai follow-up imaging pada pasien dengan AVM yang diterapi dengan radiosurgery ${ }^{15}$.

\section{KESIMPULAN}

DSA serebral yang dilakukan oleh seorang ahli neurointervensi relatif aman, baik dalam hal komplikasi neurologis, komplikasi non-neurologis maupun insiden terjadinya kematian. Komplikasi neurologis yang terjadi masih dalam batas yang direkomendasikan sesuai dengan petunjuk keamanan untuk melakukan DSA serebral. Di masa yang akan datang, tindakan DSA serebral diyakini akan semakin dibutuhkan dan memberikan manfaat yang besar bagi umat manusia.

\section{UCAPAN TERIMA KASIH}

Penulis mengucapkan terima kasih kepada seluruh anggota tim cathlab RSUD Dr. Moewardi serta Bagian Rekam Medis RSUD Dr. Moewardi yang telah membantu terlaksananya penelitian ini.

\section{DAFTAR PUSTAKA}

1. van Rooij WJ, Sprengers ME, de Gast AN. 2008. 3D-rotational angiography: the new gold standard in the detection of additional intracranial aneurysms. Am $J$ Neuradiol; 29:976-979.

2. Willinsky RA, Taylor SM, Terbrugge K, Farb RI, Omlinson G, Montanera W. 2003. Neurologic complications of cerebral angiography: prospective analysis of 2,899 procedures and review of the literature. Radiology; 227:522-528.

3. Kaufmann TJ, Houston J, Mandrekaar JN. 2007. Complication of diagnostic cerebral angiography: evaluation of 19,826 consecutive patients. Radiology; 3:812819.

4. Susanti I, Dany F. 2018. Teknologi Citra Medis Digital Subtraction Angiography (DSA) untuk Diagnostik dan Terapi Intervensi Penyakit Pembuluh Darah. Jurnal Biotek Medisiana Indonesia; 7(1):9-18.

5. Usman FS. 2014. Tingkat keamanan cerebral digital substraction angiography pada anak di beberapa rumah sakit di Indonesia. Neurona; 32(1):14-19.

6. Connors JJ, Sacks D, Furlan AJ. 2004. For the Neurovascular Coalition Writing Group. Training, competency, and credentialing standards for diagnostic cervico-cerebral angiography, carotid stenting, and cerebrovascular intervention. AJNR; 25:1732-1741.

7. Nguyen TN, Babikian VL, Romero L, Pikula A, Kase CS, Jovin TG. 2011. Intra arterial treatment methods in acute ischemic stroke. Front Neurol.; 2:1-10.

8. Barlinn K, Alexandrov AV. 2011. Vascular Imaging in Stroke: Comparative Analysis. Neurotherapeutics;8(3):340-348.

9. Dion JE, Gates PC, Fox AJ, Barnett HJM, Blom RJ. 1987. Clinical events following neuroangiography: a prospective study. Stroke; 18:997-1004.

10. Bendszus M, Koltzenburg M, Burger R, Warmuth-Metz M, Hofmann E, Solymosi L. 1999. Silent embolism in diagnostic cerebral angiography and neurointerventional procedure: a prospective study. Lancet; 354:1594-1597.

11. Short JL, Majid A, Hussain SI. 2011. Endovascular treatment of symptomatic intracranial atherosclerotic disease. Front Neurol,; 1:1-8.

12. Olesen TS, Johansen AM, Skriver E, Herning MG. 1990. Migraine with aura (classical migraine) in patients examined for cerebrovascular disease. Ugeskr Laeger; 152:1513-1515.

13. Parsons AA. 2004. Cortical spreading depression: its role in migraine pathogenesis and possible therapeutic intervention strategies. Curr Pain Headache Rep; 8:410416.

14. Kelly ME, Furlan AJ, Fiorella D. 2008. Recanalization of an acute middle cerebral artery occlusion using a self-expanding, reconstrainable, intracranial micro-stent as a temporary endovascular bypass. Stroke; 39:1770-1773.

15. Thaker NG, Turner JD, Cobb WS, Hussain I, Janjua N, He W, et al. 2012. Computed tomographic angiography versus digital subtraction angiography for the postoperative detection of residual aneurysms: a singleinstitution series and meta-analysis. $J$ NeuroIntervent Surg; 4:219-225. 